\section{Long-term treatment of} patients with idiopathic pulmonary fibrosis with nintedanib: results from the TOMORROW trial and its openlabel extension

\section{ABSTRACT}

The TOMORROW trial of nintedanib comprised a randomised, placebo-controlled, 52-week period followed by a further blinded treatment period and an open-label extension. We assessed outcomes across these periods in patients randomised to nintedanib $150 \mathrm{mg}$ twice daily or placebo at the start of TOMORROW. The annual rate of decline in FVC was $-125.4 \mathrm{~mL} /$ year $(95 \% \mathrm{Cl}-168.1$ to -82.7$)$ in the nintedanib group and $-189.7 \mathrm{~mL} /$ year $(95 \% \mathrm{Cl}-229.8$ to -149.6$)$ in the comparator group. The adverse event profile of nintedanib remained consistent throughout the studies.
These results support a benefit of nintedanib on slowing progression of idiopathic pulmonary fibrosis beyond 52 weeks.

\section{INTRODUCTION}

Idiopathic pulmonary fibrosis (IPF) is a progressive interstitial lung disease with a median survival following diagnosis of only 3 years. ${ }^{12}$ Nintedanib has been shown to slow progression of IPF in the Phase II TOMORROW $^{3}$ and Phase III INPULSIS trials. $^{4}$

Period 1 of the TOMORROW trial (NCT00514683) was a randomised, placebo-controlled, 52-week trial of four doses of nintedanib. ${ }^{3}$ Compared with placebo, nintedanib $150 \mathrm{mg}$ twice daily was associated with a reduced annual rate of decline in FVC and a lower incidence of acute exacerbations. ${ }^{3}$ Diarrhoea was the most frequent adverse event. ${ }^{3}$

Patients who completed 52 weeks' treatment in TOMORROW period 1 continued treatment in a blinded phase (period 2), until the last patient had completed 52 weeks' treatment in period 1. Patients who completed period 2 could continue/start nintedanib in an open-label extension trial (NCT01170065)

Here we present efficacy and safety data from TOMORROW periods 1 and 2 and the open-label extension.

\section{METHODS}

Online supplementary figure 1 shows the design of TOMORROW periods 1 and 2 and the extension. The inclusion criteria for period 1 have been described.

Data from patients randomised to nintedanib $150 \mathrm{mg}$ twice daily (the recommended dose of nintedanib in IPF) ${ }^{5}$ or placebo in period 1 are presented. The 'comparator group' presented comprises patients who received placebo in period 1 , nintedanib $50 \mathrm{mg}$ once daily in period 2 , and nintedanib at a range of doses between
A)

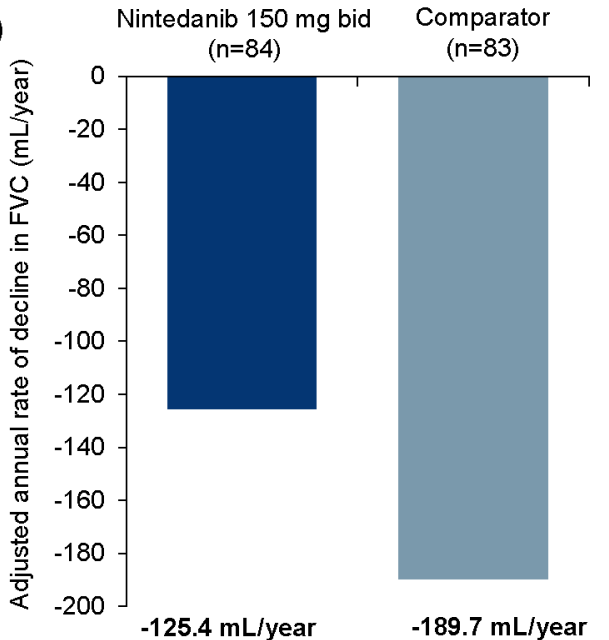

(95\% Cl: $-168.1,-82.7)(95 \% \mathrm{Cl}:-229.8,-149.6)$

c)

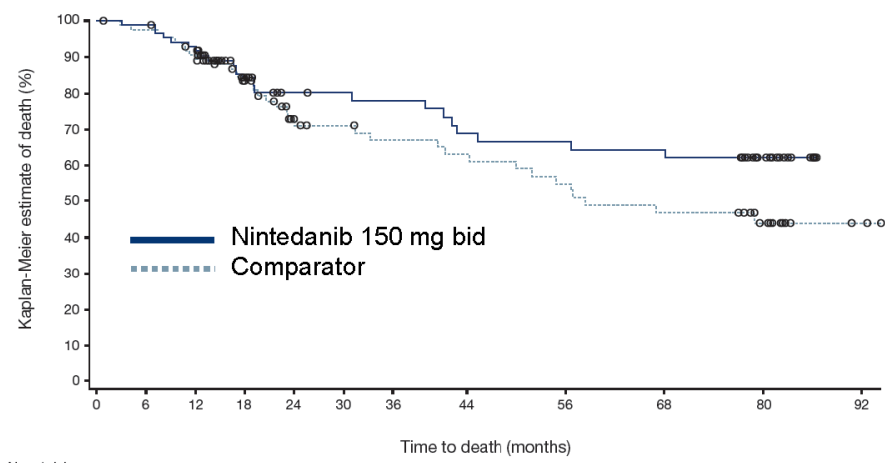

No. at risk

Nintedanib $150 \mathrm{mg}$ bid $\quad 85 \quad 8584 \quad 80 \quad 77 \quad 5949 \quad 40 \quad 36 \quad 35 \quad 35 \quad 34 \quad 34 \quad 34 \quad 33 \quad 30 \quad 2929292928 \quad 28 \quad 28 \quad 28 \quad 27 \quad 27 \quad 27 \quad 17 \quad 10 \quad 7$

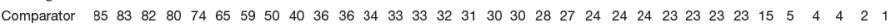

Figure 1 Annual rate of decline in FVC (A), Kaplan-Meier estimate of time to first acute exacerbation (B) and Kaplan-Meier estimate of time to death (C) over TOMORROW periods 1 and 2 and the open-label extension trial. Patients in the comparator group received placebo in period 1 of the TOMORROW trial and nintedanib $50 \mathrm{mg}$ once daily in period 2. Patients entered the extension trial on the dose that they were receiving at the end of period 2, but had the option to increase dose to nintedanib $150 \mathrm{mg}$ twice daily. Dose reduction from $150 \mathrm{mg}$ twice daily to $100 \mathrm{mg}$ twice daily and treatment interruption were permitted for the management of adverse events. 
$50 \mathrm{mg}$ once daily and $150 \mathrm{mg}$ twice daily in the extension.

All endpoints were exploratory and analysed in patients who received $\geq 1$ dose of study drug in TOMORROW period 1. Acute exacerbations were defined as in TOMORROW period $1 .^{3}$ Safety was assessed via clinical and laboratory evaluation and recording of adverse events.

The annual rate of decline in FVC was estimated using a mixed model for repeated measures with fixed effects for treatment by time, gender by height, and gender by age, random effects for patient and patient by time and a variance component variance-covariance matrix. Kaplan-Meier estimates for time to first acute exacerbation and time to death were calculated based on data collected after randomisation. Time to death was analysed using a Cox proportional hazard model adjusted for age, gender and height. Analyses were descriptive with no formal statistical comparisons between groups.

Both trials were conducted in accordance with the principles of the Declaration of Helsinki and the Harmonised Tripartite Guideline for Good Clinical Practice

Table 1 Adverse events over TOMORROW periods 1 and 2 and the open-label extension trial by MedDRA preferred term

\begin{tabular}{|c|c|c|}
\hline & $\begin{array}{l}\text { Nintedanib } 150 \mathrm{mg} \text { twice } \\
\text { daily }(\mathrm{n}=85)\end{array}$ & Comparator $(n=85)$ \\
\hline & $\mathrm{N}(\%)$ & $\mathrm{N}(\%)$ \\
\hline Any adverse event(s) & $84(98.8)$ & $83(97.6)$ \\
\hline \multicolumn{3}{|l|}{ Most frequent adverse events* } \\
\hline Diarrhoea & $63(74.1)$ & $34(40.0)$ \\
\hline Progression of IPF† & $21(24.7)$ & $27(31.8)$ \\
\hline Nausea & $23(27.1)$ & $18(21.2)$ \\
\hline Cough & $14(16.5)$ & $24(28.2)$ \\
\hline Nasopharyngitis & $14(16.5)$ & $18(21.2)$ \\
\hline Bronchitis & $13(15.3)$ & $19(22.4)$ \\
\hline Dyspnoea & $10(11.8)$ & $20(23.5)$ \\
\hline Vomiting & $16(18.8)$ & $11(12.9)$ \\
\hline Weight decreased & $15(17.6)$ & $11(12.9)$ \\
\hline Upper respiratory tract infection & $10(11.8)$ & $15(17.6)$ \\
\hline Decreased appetite & $14(16.5)$ & $6(7.1)$ \\
\hline Pneumonia & $4(4.7)$ & $13(15.3)$ \\
\hline Severe adverse event(s) $\ddagger$ & $41(48.2)$ & $50(58.8)$ \\
\hline Serious adverse event(s)§ & $47(55.3)$ & $55(64.7)$ \\
\hline Fatal adverse event(s) & $12(14.1)$ & $31(36.5)$ \\
\hline Adverse event(s) leading to treatment discontinuation & $48(56.5)$ & $49(57.6)$ \\
\hline Diarrhoea & $15(17.6)$ & $6(7.1)$ \\
\hline Progression of IPF† & $10(11.8)$ & $12(14.1)$ \\
\hline Nausea & $4(4.7)$ & $2(2.4)$ \\
\hline Abdominal pain & $3(3.5)$ & $0(0.0)$ \\
\hline Weight decreased & $3(3.5)$ & $1(1.2)$ \\
\hline Pneumonia & $0(0.0)$ & $4(4.7)$ \\
\hline
\end{tabular}

Patients in the comparator group received placebo in TOMORROW period 1 and nintedanib $50 \mathrm{mg}$ once daily in period 2. Patients entered the extension trial on the dose that they were receiving at the end of period 2 , but had the option to increase dose to nintedanib $150 \mathrm{mg}$ twice daily. Dose reduction from $150 \mathrm{mg}$ twice daily to $100 \mathrm{mg}$ twice daily and treatment interruption were permitted for the management of adverse events.

${ }^{*}$ Adverse events reported by $>15 \%$ of patients in either nintedanib $150 \mathrm{mg}$ twice daily or comparator group. tCorresponds to MedDRA term 'IPF,' which included disease worsening and IPF exacerbations.

¥Event that was incapacitating or that caused an inability to work or to perform usual activities.

$\S$ Event that resulted in death, was immediately life threatening, resulted in persistent or clinically significant

disability or incapacity, required or prolonged hospitalisation, was related to a congenital anomaly or birth defect, or was deemed serious for any other reason.

I|Adverse events leading to treatment discontinuation in $>3 \%$ of patients in either nintedanib $150 \mathrm{mg}$ twice daily or comparator group. 'Cardiac disorder adverse events' (defined according to the MedDRA system organ class) were reported in 19 patients $(22.4 \%)$ in the nintedanib $150 \mathrm{mg}$ twice daily group and 18 patients $(21.2 \%)$ in the comparator group.

IPF, idiopathic pulmonary fibrosis; MedDRA, Medical Dictionary for Regulatory Activities.

from the International Conference on Harmonisation and were approved by local authorities. Informed consent was obtained from all participants.

\section{RESULTS}

Patient characteristics at the start of period 1 were comparable across treatment groups (online supplementary table 1). Of 428 patients treated in period 1 , a total of 286 entered period 2, and 198 entered the extension, including 35 in the nintedanib $150 \mathrm{mg}$ twice daily group and 37 in the comparator group (35 of whom increased dose to nintedanib $150 \mathrm{mg}$ twice daily) (online supplementary figure 2 and supplementary table 2). Online supplementary table 3 shows patient characteristics at entry into the extension. Mean (SD) total exposure was 27.6 (26.5) months for nintedanib and 28.1 (23.1) months for comparator (online supplementary table 4). Online supplementary table 5 shows exposure by trial and treatment.

The adjusted annual rate of decline in FVC was $-125.4 \mathrm{~mL} /$ year $\quad(95 \% \mathrm{CI}$ -168.1 to -82.7$)$ for nintedanib and $\quad-189.7 \mathrm{~mL} /$ year $\quad(95 \% \mathrm{CI}$ -229.8 to -149.6$)$ for comparator (figure 1A). The proportion of patients with $\geq 1$ acute exacerbation was $12.9 \%$ for nintedanib and $25.9 \%$ for comparator. Based on analyses of time to first acute exacerbation, the probability of having an acute exacerbation was $30.5 \%$ with nintedanib and $48.3 \%$ with comparator (figure 1B). Overall, 22 patients $(25.9 \%)$ died in the nintedanib group and $34(40.0 \%)$ died in the comparator group (figure 1C). Further efficacy analyses are presented in the online supplementary material. Table 1 shows a summary of adverse events.

\section{DISCUSSION}

In period 1 of the TOMORROW trial, nintedanib $150 \mathrm{mg}$ twice daily was associated with a reduced rate of decline in FVC and fewer acute exacerbations versus placebo over 52 weeks. ${ }^{3}$ Our analyses suggest that the efficacy of nintedanib $150 \mathrm{mg}$ twice daily was maintained beyond 52 weeks. The small difference in FVC decline over TOMORROW periods 1 and 2 and the extension between the nintedanib $150 \mathrm{mg}$ twice daily and comparator groups was not unexpected, as most patients in the comparator group received nintedanib $150 \mathrm{mg}$ twice daily in the extension.

The annual rate of decline in FVC in the nintedanib group reported here is similar to that observed in the nintedanib $150 \mathrm{mg}$ twice daily group in the Phase III INPULSIS trials $(-113.6 \mathrm{~mL} / \text { year })^{4}$ In a pooled 
analysis of data from 1231 patients in TOMORROW period 1 and the INPULSIS trials, the annual rate of decline in FVC was $-112.4 \mathrm{~mL} /$ year with nintedanib $150 \mathrm{mg}$ twice daily and $-223.3 \mathrm{~mL} /$ year with placebo (difference $110.9 \mathrm{~mL} /$ year $(95 \% \mathrm{CI}$ 78.5 to 143.3$) ; \mathrm{p}<0.0001)^{7}$

Consistent with our analyses, in the pooled analysis of data from TOMORROW period 1 and the INPULSIS trials, nintedanib was associated with a significant reduction in the risk of acute exacerbation (HR 0.53 (95\% CI 0.34 to $0.83) ; \mathrm{p}=0.0047$ ) and a numerical reduction in the risk of all-cause mortality (HR 0.70 (95\% CI 0.46 to 1.08$) ; \mathrm{p}=0.0954){ }^{7}$

No relevant changes in the safety and tolerability of nintedanib were identified in our analysis of long-term data. A similar adverse event profile has been observed in INPULSIS-ON, the open-label extension of the INPULSIS trials. ${ }^{8}$

Limitations of our analyses include switches in treatments and doses that prevented statistical comparisons being made between groups; the lack of a true placebo group; and the potential for selection bias in patients who continued into the extension. Our analyses excluded patients who died or were unable to enter the extension due to disease progression. The small patient numbers available for analyses beyond period 1 means these results may underestimate the rate of FVC decline, particularly in the comparator group, in which most patients received nintedanib $150 \mathrm{mg}$ twice daily in the extension.

In conclusion, results from the TOMORROW trial and its open-label extension support an effect of nintedanib on slowing the progression of IPF beyond 52 weeks. No new safety signals were identified with up to 86 months of treatment.

\section{Luca Richeldi, ${ }^{1}$ Michael Kreuter, ${ }^{2}$ Moisés Selman, ${ }^{3}$ Bruno Crestani, ${ }^{4}$ Anne-Marie Kirsten, ${ }^{5}$ Wim A Wuyts, ${ }^{6}$ Zuojun $\mathrm{Xu}^{7}$ Katell Bernois, ${ }^{8}$ Susanne Stowasser, ${ }^{9}$ Manuel Quaresma, ${ }^{2,9}$ Ulrich Costabel $^{10}$}

${ }^{1}$ National Institute for Health Research Southampton Respiratory Biomedical Research Unit and Clinical and Experimental Sciences, University of Southampton, Southampton, UK

${ }^{2}$ Center for Interstitial and Rare Lung Diseases, Department of Pneumology, Thoraxklinik, University of Heidelberg, and Translational Lung Research Center Heidelberg, German Center for Lung Research Germany, Heidelberg, Germany

${ }^{3}$ Instituto Nacional de Enfermedades Respiratorias, Mexico City, Mexico

${ }^{4}$ Hôpital Bichat, Pneumologie, Paris, France

${ }^{5}$ Pulmonary Research Institute at Lung Clinic

Grosshansdorf, Airway Research Center North, German

Center for Lung Research, Grosshansdorf, Germany
${ }^{6}$ Department of Respiratory Medicine, University Hospitals Leuven, Leuven, Belgium

${ }^{7}$ Peking Union Medical College Hospital, Beijing, China

${ }^{8}$ Boehringer Ingelheim France S.A.S., Paris, France

${ }^{9}$ Boehringer Ingelheim Pharma GmbH \& Co. KG, Ingelheim am Rhein, Germany

${ }^{10}$ Ruhrlandklinik, University Hospital, University of

Duisburg-Essen, Essen, Germany

Correspondence to Professor Luca Richeldi, National Institute for Health Research Southampton Respiratory Biomedical Research Unit and Clinical and Experimental Sciences, University of Southampton, Southampton S017 1BJ, UK; luca.richeldi@me.com

Acknowledgements Medical writing assistance, supported financially by Boehringer Ingelheim, was provided by Julie Fleming of FleishmanHillard Fishburn, London, UK, and Lauren Liss of Boehringer Ingelheim Pharma GmbH \& Co. KG, during the preparation of this article. The authors were fully responsible for all content and editorial decisions, and were involved at all stages of manuscript development and have approved the final version.

Contributors LR, MS and UC contributed to the design of the TOMORROW trial. KB contributed to the analysis of data. All the authors were involved in the interpretation of data and in writing or revising the manuscript. LR takes responsibility for the integrity of the work in this manuscript and is the guarantor of the manuscript.

Funding The TOMORROW trial and its open-label extension trial were funded by Boehringer Ingelheim.

Competing interests $L R$ reports receipt of personal fees from Boehringer Ingelheim for being a coprincipal investigator and member of the steering committee for the INPULSIS trials; grants and personal fees for being an advisory board member from InterMune; personal fees from Medlmmune, Roche and Takeda for being an advisory board member; consulting fees from Biogen Idec, Celgene, ImmuneWorks, Pliant Therapeutics and Sanofi-Aventis; speaker honoraria from Shionogi. MK reports receipt of grants and personal fees from Boehringer Ingelheim, InterMune and Roche. MS reports receipt of personal fees from Boehringer Ingelheim for being a member of the INPULSIS steering committee. BC reports receipt of grants, personal fees and non-financial support from Boehringer Ingelheim and InterMune; personal fees and non-financial support from Sanofi; grants from Cardif and Medlmmune; and personal fees from AstraZeneca. A-MK reports receipt of grants (paid to her institution) and lecture fees from Boehringer Ingelheim. WAW reports receipt of grants (paid to his institution) from InterMune and travel costs for congresses from Boehringer Ingelheim, Roche and Bayer. ZX reports no competing interests. KB, SSt and $\mathrm{MQ}$ are employees of Boehringer Ingelheim. UC reports receipt of grants (paid to his institution); personal fees for consulting and lecture fees from Boehringer Ingelheim, InterMune and Bayer; and personal fees for consulting from AstraZeneca, Biogen, Centocor, FibroGen, Gilead, GlaxoSmithKline, Roche and UCB Celltech.

Patient consent Obtained.

Ethics approval The study was approved by an IRB at every site.

Provenance and peer review Not commissioned; externally peer reviewed.

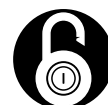

OPEN ACCESS
Open Access This is an Open Access article distributed in accordance with the Creative Commons Attribution Non Commercial (CC BY-NC 4.0) license, which permits others to distribute, remix, adapt, build upon this work non-commercially, and license their derivative works on different terms, provided the original work is properly cited and the use is noncommercial. See: http://creativecommons.org/licenses/ by-nc/4.0/

(C) Article author(s) (or their employer(s) unless otherwise stated in the text of the article) 2018. All rights reserved. No commercial use is permitted unless otherwise expressly granted.

- Additional material is published online only. To view please visit the journal online (http://dx.doi.org/ 10.1136/thoraxinl-2016-209701).

\section{Check for updates}

To cite Richeldi L, Kreuter M, Selman M, et al. Thorax 2018;73:581-583.

Received 9 November 2016

Revised 19 July 2017

Accepted 31 July 2017

Published Online First 9 October 2017

Thorax 2018:73:581-583.

doi:10.1136/thoraxjnl-2016-209701

\section{REFERENCES}

1 Raghu G, Collard HR, Egan JJ, et al. An official ATS/ ERS/JRS/ALAT statement: idiopathic pulmonary fibrosis: evidence-based guidelines for diagnosis and management. Am J Respir Crit Care Med 2011;183:788-824.

2 Ley B, Collard HR, King TE. Clinical course and prediction of survival in idiopathic pulmonary fibrosis. Am J Respir Crit Care Med 2011:183:431-40.

3 Richeldi L, Costabel U, Selman M, et al. Efficacy of a tyrosine kinase inhibitor in idiopathic pulmonary fibrosis. N Engl J Med 2011;365:1079-87.

4 Richeldi L, du Bois RM, Raghu G, et al. Efficacy and safety of nintedanib in idiopathic pulmonary fibrosis. N Engl J Med 2014;370:2071-82.

5 Boehringer Ingelheim Pharmaceuticals, Inc. OFEVTM (nintedanib) prescribing information. 2016. http:// bidocs.boehringer-ingelheim.com/BIWebAccess/ ViewServlet.ser?docBase=renetnt\&folderPath $=$ I Prescribing+Information/PIs/Ofev/ofev.pdf (accessed 21 Apr 2016)

6 Boehringer Ingelheim. Ofev (nintedanib) summary of product characteristics. 2016. http://www.ema.europa. eu/ema/index.jsp?curl=pages/medicines/human/ medicines/003821/human_med_001834.jsp\&mid= WC0b01ac058001d124 (accessed 21 Apr 2016).

7 Richeldi L, Cottin V, du Bois RM, et al. Nintedanib in patients with idiopathic pulmonary fibrosis: combined evidence from the TOMORROW and INPULSIS $®$ trials. Respir Med 2016;113:74-9.

8 Crestani B, Quaresma M, Kaye M, et al. Longterm treatment with nintedanib in patients with IPF: an update from INPULSIS $®-O N$. Eur Respir J 2016;48(Suppl 60):0A4960. 